\title{
Selective Termination of Pregnancy: About a Case of Anencephaly on a Bi-Chorial Twin Pregnancy
}

\author{
C. Tshabu Aguemon ${ }^{*}$, S. Lokossou², M. Ogoudjobi², S. Kamga ${ }^{3}$, B. Matabishi', M. Diab ${ }^{3}$, \\ M. Sinou ${ }^{1}$ \\ ${ }^{1}$ Centre National Hospitalier et Universitaire-HKM, Cotonou, Benin \\ ${ }^{2}$ Centre Hospitalier Universitaire-OP, Porto-Novo, Benin \\ ${ }^{3}$ Center Hospitalier d'Arpajon, Arpajon, France \\ Email: *caguemon@yahoo.fr
}

How to cite this paper: Aguemon, C.T., Lokossou, S., Ogoudjobi, M., Kamga, S., Matabishi, B., Diab, M. and Sinou, M. (2018) Selective Termination of Pregnancy: About a Case of Anencephaly on a Bi-Chorial Twin Pregnancy. Open Journal of Obstetrics and Gynecology, 8, 315-320.

https://doi.org/10.4236/ojog.2018.84034

Received: February 22, 2018

Accepted: April 7, 2018

Published: April 10, 2018

Copyright $\odot 2018$ by authors and Scientific Research Publishing Inc. This work is licensed under the Creative Commons Attribution International License (CC BY 4.0).

http://creativecommons.org/licenses/by/4.0/

(c) (i) Open Access

\begin{abstract}
Background: The discovery of a lethal or disabling malformation requires a thoughtful decision in the event of a termination of pregnancy on medical grounds. The termination of pregnancy can be selective in the case of multiple pregnancies if a twin is suffering from a serious condition. Objective: To report a case of anencephaly on a twin pregnancy and conduct a review of literature. Case: This is a 30-year-old woman carrying a pregnancy obtained after the third attempt at in vitro fertilization (IVF) with transfer of two embryos. No risk factor was found on this pregnancy except for the twinning. The diagnosis was made at 14 weeks +1 day during first term ultrasound, which discovered an on-going bi-chorial bi-amniotic twin pregnancy, with twin B (TB) carrying a defect on his head. A selective interruption was performed on TB at 16 weeks by cordonal injection with potassium chloride. The pregnancy went on without incident and with spontaneous vaginal delivery of the second twin at 39 weeks of pregnancy. Despite the selective termination, the pregnancy went on without any complication. Conclusion: Anencephaly on twin pregnancy is a rare occurrence. In a bichorial pregnancy, a selective feticide can improve the gestational age at birth.
\end{abstract}

\section{Keywords}

Anencephaly, Selective Interruption, Twin Pregnancy

\section{Introduction}

Ultrasound remains virtually the only tool for detecting fetal malformations. 
Several malformations may be found, including abnormalities in the cranial vault. The severity of malformations varies. The discovery of a lethal or disabling malformation requires preparation of the parents to a difficult psychological situation, and a thoughtful decision in the event of a termination of pregnancy on medical grounds.

The termination of pregnancy can be selective in the case of multiple pregnancies if a twin is suffering from a serious condition. Thus, a selective feticide is envisioned after antenatal diagnosis of a severe chromosomal or morphological anomaly incompatible with extra-uterine life. In the case of a twin pregnancy, the problem is that of the survival of the second twin and the evolution of the pregnancy after the feticide.

\section{Objectives}

Reporting a case of selective pregnancy termination (SPT) for anencephaly on twin pregnancy, outlining the prognosis of the second twin and reviewing the literature.

\section{Method}

We have studied a case of a bichorial bi amniotic twin pregnancy obtained by medically assisted procreation. During the first term ultrasound a twin was diagnosed with anencephaly and the other without abnormality. We participated in a multidisciplinary meeting during which the decision of pregnancy termination was taken. The case was collected at the Arpajon hospital in France. We undertook a literature review.

Ethical Concern: We obtained verbal agreement from the patient for publication. Anonymity was guaranteed.

\section{Observation}

Our patient was a 30-year-old pregnant woman, of French origin. In her history we noted a secondary infertility of male origin, namely oligoasthenoteratospermia. Her obstetrical record noted two pregnancies and one delivery which led to a child in good health.

Her second pregnancy was obtained after the third attempt at implantation during a medically-assisted in vitro fertilization (IVF). Two embryos were transferred in December 2015 in a private hospital in France. The ultrasound carried out on February 2016 at Arpajon hospital revealed a bichorial bi-amniotic twin pregnancy with two foetuses showing cardiac activity. Foetal biometry correlates with 14 weeks of amenorrhea (WA) +1 day for twin A (TA) and 13 weeks for TB. Morphological analysis found an anomaly of the cranial vault in TB (Table 1). Faced with this, the patient is referred for better management. A second ultrasound carried out by the referent practitioner confirmed the abnormality in $\mathrm{TB}$, with an open neural tube defect (Figure 1). Given the poor prognosis of TB's malformation, the couple immediately requested for a selective termination 
Table 1. Foetal biometrics and morphology.

\begin{tabular}{c}
\hline Biometrics (mm) and morphology \\
Cranio-caudal length \\
Nuchal translucency \\
Cranial vault \\
Brain \\
\hline Absence of cranial vault \\
valas dope-15112015
\end{tabular}

(a)

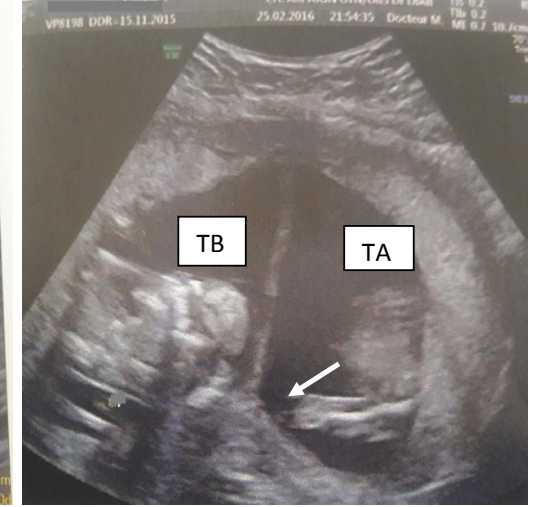

(b)

Figure 1. First term ultrasound. (a) Sagittalsection of foetus showing exencephaly; (b) (TB) Sign of hyperechogenic lambda.

of pregnancy (STP). The case of this patient was discussed in a prenatal diagnosis multidisciplinary meeting on March 2016. The decision of STP in TB was taken, coupled with an amniocentesis on TA.

The STP is uneventful, carried out by intra-cordonal injection of potassium chloride into TB causing cardiac arrest. A sampling of TB's amniotic fluid for a karyotype was then carried out after withdrawal of the needle from the umbilical cord. The test results were normal and revealed that the foetus was male. However, after further discussions with the couple, it was decided that amniocentesis on TA should no longer be performed, to reduce the risks of miscarriage involved in the context of IVF. Vitality of TA was controlled during the same ultrasound, then checked thirty minutes later. The woman was then received for ultrasound check a week later. The pregnancy continued without incident on TA (Table 2). The patient was monitored monthly; obstetric ultrasounds in the second and third term showed no morphological anomaly. Throughout the pregnancy, foetal biometrics remained in line with gestational age. The pregnancy thus pursued, the patient spontaneously delivered TA, a female infant, by vaginal route at 39 weeks +1 day under epidural anaesthesia, the Apgar score was 10at the first and fifth minutes, followed by a mummified TB, male.

\section{Comments and Literature Review}

Anencephaly is a central nervous system congenital malformation due to an open neural tube defect which concerns the cephalic area and results in a partial 
Table 2. Biometric evolution of normal foetus after STP.

\begin{tabular}{cccc}
\hline Term & 17 WA + & $24 \mathrm{WA}+5$ & $30 \mathrm{WA}+5$ \\
Biometrics (mm) & 36.5 & 60.6 & 77.8 \\
Bi-parietal diameter & 139.6 & 227.3 & 279.8 \\
Cephalic perimeter & 120.1 & 194.1 & 258.7 \\
Abdominal perimeter & 26.3 & 44.1 & 51.8 \\
Femoral length & 209 & 687 & 1538 \\
\hline
\end{tabular}

or total absence of the brain, skull and scalp. It affects 1.4 to 4.7 per 1000 births [1]. It is sometimes associated with spina bifida or omphalocele [2] and may take part in a polymalformative syndrome [3]. The causes of anencephaly remain unknown. The Congolese and Moroccan studies respectively incriminate consumption of potatoes infested with Phytophthora infestans and of Fenugreek in periconceptional period [4] [5] [6]. An epidemiological study [2] incriminates maternal hyperthermia, insufficiency or excess of certain nutrients, chronic diseases, and certain chemical agents. In our case, none of these factors were found to explain the occurrence of anencephaly. Antenatal diagnosis of anencephaly is possible as from the first term. The ultrasound image is that of an exencephaly, the precursor of anencephaly, characterized by the absence of cranial vault and dura mater, while cerebral tissue floats in the amniotic fluid [7]. This demonstrates the value of first term ultrasound for monitoring pregnancy. In our study, the diagnosis was made at 14 Weeks +1 day whereas several African studies indicate a late first ultrasound. In particular Amadou et al. [8], in Togo about a series of six cases of anencephaly on twin pregnancies, indicate a diagnosis made during second or third terms.

The anencephalic twin can be a part of a monochorial or a bichorial twin pregnancy [9] [10]. This knowledge is essential to the treatment as it conditions the technique used for the interruption. Bichorial and monochorial twin pregnancies must be treated differently. The major risks associated with anencephaly on twin pregnancies are hydramnios and premature delivery.

In an English series carried out on 2329 twin pregnancies from 1998 to 2002, the rate of hydramnios was $36 \%$ [11]. Another series [12] reports $57 \%$ of hydramnios in bichorial twin pregnancies; we can therefore say that the selective feticide in our study allowed the pregnancy to proceed normally avoiding hydramnios, and reducing the risk of premature delivery [10] [13] [14].

In developing countries, on the other hand, selective feticide is not always feasible, exposing the pregnancy to hydramnios with its risks including rupture of membranes and premature delivery. It should be noted, however, that this complication may be counterbalanced in cases of mono-amniotic pregnancy by the swallowing of amniotic fluid by the normal foetus [15].

Apart from these two main risks, there was $7.9 \%$ risk of miscarriage and $12.4 \%$ risk of premature delivery between 25 and 32 weeks in Evans et al's study [16]. 
Due to the risk of prematurity, it may be wise to wait 32 to 34 weeks to conduct the selective interruption [17]. In Evans' series [16], 16 of 345 twin pregnancies showed that the risk of foetal loss was not influenced by the age at which the selective termination was carried out. The risk ranged from 5.4\% to $9 \%$ after 25 gestation's weeks. Today, this risk has been significantly reduced by improved techniques and ultrasound performance. It was carried out at 16 weeks +2 days in our study, without incident on the pregnancy. The natural history of mono-chorial pregnancies shows a risk of in-utero death of the anencephalic foetus (20\%), which may lead to brain damage or death of the normal foetus [9] [18]. Some authors [1] [9] [15] [17] have obtained good results by adopting simple monitoring with amnio-drainage. On the other hand, others authors choosea more radical treatment, like coagulation of the umbilical cord using bipolar forceps, with an overall survival rate at birth of $72 \%$ for the second twin. The series of Amadou et al. reveals that this survival rate is very low in developing countries where selective termination is not feasible. The survival rate is $33 \%$ with simple monitoring. In the absence of amniodrainage, hydramnios would be the principal cause of death by induced prematurity [8].

\section{Conclusion}

Anencephaly on twin pregnancy is rare. Ultrasound allows early diagnosis and treatment, in order to reduce the mortality of the normal twin. In bi-chorial pregnancies, a selective feticide can increase gestational age at birth. The risks of this act are miscarriage and premature birth which must be taken into account and discussed with the couple.

\section{References}

[1] Wilson, P.L., Goodman, J.R., Smith, K.M. and Wagner, A.F. (2009) Monochorionic Diamniotic Twins Concordant for Anencephaly: A Case Report. Journal of Reproductive Medicine for the Obstetrician and Gynecologist, 54, 401-403.

[2] Padmanabhan, R. (2006) Etiology, Pathogenesis and Prevention of Neural Tube Defects. Congenital Anomalies (Kyoto), 46, 55-67. https://doi.org/10.1111/j.1741-4520.2006.00104.x

[3] Shetty, B.P., Alva, N., Patil, S. and Shetty, R. (2012) Meckel-Gruber Syndrome (Dysencephalia Splanchnocystica). The Journal of Contemporary Dental Practice, 13, 713-715.

[4] Mohammed, A.R., Naima, C., Loubna, B., Laila, E., Khalid, L. and Amina, B. (2013) Risk Factors of Congenital Malformations: A Prospective Study at the Souissi Maternity Clinic in Rabat, Morocco. Journal of Pediatrics and Child Care, 26, 198-203.

[5] Iloki, L.H., Azika, M.E. and Ikourou, Y.P. (1993) Anencephaly: 10 Cases Found in the Three Years in Brazzaville (Congo). Journal De Gynecologie Obstetrique Et Biologie De La Reproduction, 22, 621-624.

[6] Grange, G. and Bargy, F. (2016) A Practical Guide to Obstetric and Gynecological Ultrasound. 2nd Edition, Masson, 135-136.

[7] Amadou, A., Sonhaye, L., Douaguibe, B., Tchaou, M., Agoda-Koussema, L.K., Etteh, A.K. and N'Dakena, K. (2013) Anencephaly in Twin Pregnancy: A Series of 6 Cases. 
Medecine et Sante Tropicales, 23, 185-188.

[8] Vandecruys, H., Avgidou, K., Surerus, E., Flack, N. and Nicolaides, K.H. (2006) Dilemmas in the Management of Twins Discordant for Anencephaly Diagnosed at 11 +0 to $13+6$ Weeks of Gestation. Ultrasound in Obstetrics \& Gynecology, 28, 653-658. https://doi.org/10.1002/uog.2836

[9] Lust, A., De Catte, L., Lewi, L., Deprest, J., Latch, P. and Devlieger, R. (2008) Monochorionic and Dichorionic Twin Pregnancies Discordant for Fetal Anencephaly: A Systematic Review of Prenatal Management Options. Prenatal Diagnosis, 28, 275-279. https://doi.org/10.1002/pd.1967

[10] Glinianaia, S.V., Rankin, J. and Wright, C. (2008) Congenital Anomalies in Twins: A Register-Based Study. Human Reproduction, 23, 1306-1311. https://doi.org/10.1093/humrep/den104

[11] Vandecruys, H., Avgidou, K., Surerus, E., et al. (2006) Dilemmas in the Management of Twins Discordant for Anencephaly Diagnosed at $11+0$ to $13+6$ Weeks of Gestation. Ultrasound in Obstetrics \& Gynecology, 28, 653-658. https://doi.org/10.1002/uog.2836

[12] Leeker, M. and Beinder, E. (2004) Twin Pregnancies Discordant for Anencephaly Management, Pregnancy Outcome and Review of Literature. European Journal of Obstetrics \& Gynecology, 114, 15-18. https://doi.org/10.1016/j.ejogrb.2003.09.013

[13] Sebire, N.J., Sepu lveda, W. and Hughes, K. (1997) Management of Twin Pregnancies Discordant for Anencephaly. British Journal of Obstetrics \& Gynecology, 104, 216-219. https://doi.org/10.1111/j.1471-0528.1997.tb11048.x

[14] Lim, K.I., Dy, C., Pugash, D. and Williams, K.P. (2005) Monoamniotic Twins Discordant for Anencephaly Managed Conservatively with Good Outcome: Two Case Reports and a Review of the Literature. Ultrasound in Obstetrics \& Gynecology, 26, 188-193. https://doi.org/10.1002/uog.1947

[15] Evans, M.I., Goldberg, J.D., Horenstein, J., et al. (1999) Selective Termination for Structural Chromosomal, and Mendeliananomlies: International Experience. American Journal of Obstetrics \& Gynecology, 181, 893-897. https://doi.org/10.1016/S0002-9378(99)70321-2

[16] Hern, W.M. (2004) Seletive Termination for Fetal Anomaly/Genetic Disorder in Twin Pregnancy at 32+ Menstrual Weeks. Report of Four Cases. Fetal Diagnosis and Therapy, 19, 292-295. https://doi.org/10.1159/000076714

[17] Favre, R. (2009) Discordant Anomaly in Twin Pregnancy. Journal de Gynécologie Obstétrique et Biologie de la Reproduction, 38, S90-S99. https://doi.org/10.1016/S0368-2315(09)73565-3

[18] Rossi, A.C. and D'Addario, V. (2009) Umbilical Cord Occlusion for Selective Feticide in Complicated Monochorionics: A Systematic Review of Literature. American Journal of Obstetrics \& Gynecology, 200, 1223-1229. 